\title{
Movimiento mapuche: recuperando Territorio Político Convencional para el siglo XXI
}

\author{
Mapuche Movement: Recovering Conventional Political Territory \\ for the 21st Century
}

Victor Tricot Salomón*

\begin{abstract}
Resumen: El presente artículo analiza la emergencia del movimiento mapuche en el escenario político, planteando que la demanda por territorio no se circunscribe sólo a un espacio físico, sino que es por esencia, política. Siendo la política convencional también un territorio a recuperar para el movimiento mapuche en Chile. El objetivo primordial consiste en analizar cómo la lucha desde lo institucional y la disputa por el poder pueden haber contribuido como forma de descolonización, como un repertorio más dentro de aquellas utilizadas por el movimiento mapuche.
\end{abstract}

Palabras clave: Movimiento mapuche, recuperación territorial, participación política, descolonización.

\begin{abstract}
The following article analyses the emergence of the mapuche movement in the political arena, here we state that the demand for territory does not only imply physical space, but also and is in essence a political demand. Being in this context, conventional politics also a territory to recuperate for the mapuche movement in Chile. The main objective consists in analyzing how the struggle from within the institutions and for power may have contributed as a way of decolonization, as another repertoire among those used by the mapuche movement.
\end{abstract}

Keywords: Mapuche Movement, Territorial Recuperation, Political Participation, Decolonization

Recibido: 24 mayo 2017

Aceptado: 14 octubre 2017

\section{Introducción}

Los pueblos indígenas han asumido, especialmente durante las últimos dos décadas, en base a participación, organización y movilización social, un sitial entre los actores protagónicos de la política latinoamericana. Pese a que un repaso sucinto de la historia del continente permite encontrar una miríada de ejemplos de la manera en la cual los pueblos indígenas han resistido a la colonización, tanto hispana como de los Estados nacionales creados con

\footnotetext{
* Chileno, Doctor Procesos Políticos Contemporáneos Universidad de Salamanca, SIT Study Abroad, Tokichen18@gmail.com
} 
posterioridad a las independencias, en estas últimas décadas han logrado una presencia, participación e influencia casi inimaginables hace sólo unos años, caracterizándose muchas veces desde la literatura como una coyuntura de emergencia de los pueblos indígenas ${ }^{1}$. Dicho aserto no deja de ser controvertido, toda vez que pareciera sugerir que previo a ese momento la expresión indígena movimental no hubiese existido. Lo cierto es que más allá de aquello, hay un espacio del quehacer continental donde definitivamente sí han emergido, y desde dónde evidentemente fueron relegados por gran parte de la historia de América Latina, esta es la arena política del continente.

Esta emergencia en el escenario político ha tenido como resultado la concreción de derechos y la presencia de la temática indígena en la agenda de gran parte de los países del continente. Sin embargo, estas transformaciones no han significado necesariamente un verdadero cambio en el modo en el cual muchos de los Estados latinoamericanos se relacionan con sus pueblos indígenas. Persistiendo de esta manera algunas variaciones, una relación de dominación, expresión de lo que Aníbal Quijano denomina colonialidad del poder $^{2}$, plasmándose está a nivel societal, político, económico, institucional e inclusivo en la cultura de los diferentes países latinoamericanos. Esta relación de dominación no se circunscribe a lo teórico o epistémico, sino que también plantea un desafío multidimensional permanente y tangible a los indígenas del continente. De esta forma vemos desde el movimiento indígena la elaboración de una teoría y práctica decolonial que puede evidentemente asumir formas diversas, así como se reconstruye y construye un pensamiento descolonizado, de la misma manera resulta relevante la necesidad de descolonizar otros ámbitos del contexto en el cual se desenvuelven estos pueblos, a saber, la historia, relaciones sociales y por cierto la política. Siendo en este marco en el cual la lucha por el territorio se torna medular entre las demandas indígenas latinoamericanas.

El territorio como lugar de disputa extendió la demanda indígena de la primigenia reclamación por tierra hacia el terreno de lo político, convirtiéndose el territorio en un espacio simbólico y concreto en el cual se gestaba y desarrollaba la lucha de los pueblos indígenas, un espacio poliédrico cimentado en nociones cosmovisionales, prácticas culturales, sociales, mnemónicas, identitarias y donde la acción colectiva asumía múltiples rostros.

En este artículo lo que se pretende es profundizar en el conocimiento de una de estas aristas, intentando mostrar cómo la demanda y la lucha por el territorio no se limita sólo a la disputa por un espacio físico, sino que es por esencia, política. Para estudiar lo anterior se ahondará en el caso del pueblo y el movimiento mapuche. En este sentido, es que cabe preguntarse si es que puede entenderse la participación en política convencional como un repertorio más de recuperación territorial en un contexto endocolonial como es el chileno.

Este artículo se construye sobre dos premisas centrales, por un lado, entendemos que la política convencional es también un territorio a recuperar por parte del movimiento mapuche en Chile; y por otra, que no puede existir en el siglo XXI una democracia

${ }^{1}$ José Bengoa, La emergencia indígena en América Latina, Fondo de Cultura Económica, 2000.

2 Aníbal Quijano, "El Movimiento indígena y las cuestiones pendientes en América Latina", Argumentos UAM-X, México. 
consolidada en el país que relegue o excluya a los pueblos indígenas de la política convencional y de las instituciones políticas. Se propone analizar el rol y la utilización de la política convencional por parte del movimiento mapuche ${ }^{3}$. El objetivo no es cuantificar impacto, sino que ver cómo la lucha desde lo institucional y la disputa por el poder pueden haber contribuido como forma de descolonización, como un repertorio más dentro de aquellas utilizadas por el movimiento mapuche.

Con estos objetivos en vista, es que este texto abordará qué se entiende por una relación colonial de dominación, colonialismo interno y territorio en el marco de la lucha mapuche, para posteriormente analizar la manera en la cual se ha manifestado la participación política convencional en el marco del conflicto del Estado de Chile con los mapuche y cómo se liga al concepto de territorio.

\section{Colonialidad y territorio}

Debemos preguntarnos ¿es posible hablar de territorio más allá de lo tangible, de la concepción occidental de propiedad privada? Antes de poder profundizar en esta pregunta es necesario entender el contexto en el cual se desenvuelve el movimiento mapuche en Chile.

Verificada la invasión al territorio mapuche, el Estado de Chile instaura y consolida para con el pueblo mapuche una relación de dominación. Como el resto de los pueblos indígenas en el país, son asimilados, fagocitados por la idea de que en este nuevo Estado chileno sólo cabe una nación. Se inicia de esta forma una dialéctica de dominadodominador o colonizado colonizador, donde los pueblos indígenas se llevan la peor parte en esta distribución del poder. Lo anterior, no ha variado en lo sustancial, pudiéndose argumentar una pervivencia de una configuración del poder, tanto en Chile como en América Latina sustentada en relaciones de dominación excluyentes, jerarquizadas y erigidas sobre una permanente y persistente herida colonial ${ }^{4}$.

En términos concretos, al remitirse a la idea de colonialidad se estaría haciendo referencia a un proceso complejo multidimensional que persistiría aún en la actualidad, con manifestaciones concretas que exceden lo meramente racial o étnico. En otras palabras, es posible afirmar que la colonialidad se manifiesta "a través de la naturalización de jerarquías territoriales, raciales, culturales y epistémicas, posibilitando la re-producción de relaciones de dominación; este patrón de poder no sólo garantiza la explotación del capital de unos seres humanos por otros a escala mundial, sino también la subalternización y obliteración de los conocimientos, experiencias y formas de vida de quienes son dominados y explotados" $"$ Existiría en América Latina una naturalización de la colonialidad como forma

\footnotetext{
${ }^{3}$ Es importante señalar que al hacer referencia al movimiento mapuche se estará hablando concretamente de la parte de éste que ha sido caracterizado como autonomista. Se entiende la existencia de otros segmentos del movimiento que no adhieren con esta idea, ergo la aclaración.

${ }^{4}$ Walter Mignolo, La idea de américa Latina. La herida colonial y la opción decolonial, 2007.

${ }^{5}$ Eduardo Restrepo, Inflexión decolonial: fuentes, conceptos y cuestionamientos, Editorial Universitaria del Cauca.
} 
de organización y praxis del poder, un patrón de poder que tiene manifestaciones en diversos ámbitos societales, culturales, epistemológicos y, por cierto, políticos.

En Chile lo expuesto tendría su expresión política en la poca presencia y relevancia de experiencias sistemáticas de participación de los indígenas y concretamente de los mapuche en la vida política convencional, institucional, electoral y por sobre todo representativas del país. Es cierto que es posible encontrar organización y lucha mapuche prácticamente desde el final de la invasión de su territorio, pero lo concreto es que la presencia y participación de éstos fueron siempre relegadas a un rol secundario y en el marco de una clara expresión de relaciones asimétricas donde la inclusión de sus demandas, necesidades o cosmovisiones no forman parte del Estado-nación chileno.

Es posible afirmar que se establece a contar de entonces -como lo ha referido el sociólogo mexicano Pablo González Casanova- una relación de colonialismo interno, una situación en la cual el pueblo indígena es una colonia en el interior del país. Al aludirse a este concepto se nos remite a relaciones sociales de dominio y explotación que se produce históricamente por la conquista de unos pueblos sobre otros, concretamente los pueblos de América Latina perdieron su autonomía, siendo en general considerados en una categoría inferior por debajo de naciones dominantes, además de no participar "en los más altos cargos políticos y militares del gobierno central, salvo en condiciones de "asimilados". Este colonialismo interno, no sólo corresponde a políticas de Estado o a las instituciones que de ella proceden, sino que va más allá representando una "gramática social muy vasta que atraviesa la sociabilidad, el espacio público y el espacio privado la cultura, las mentalidades y subjetividades"7.

En la misma línea, es que Boaventura de Sousa Santos afirma la dificultad para el progresismo latinoamericano de soñar con el fin del colonialismo, siendo el anticapitalismo su único objetivo legítimo ${ }^{8}$. No obstante lo afirmado, lo cierto es que los pueblos indígenas del continente sí han logrado interpelar el colonialismo, extendiendo la incapacidad onírica planteada por de Sousa. Con mayor o menor éxito, el movimiento indígena en América Latina ha sido capaz no sólo de soñar, sino que además de luchar en distintos ámbitos por confrontar este patrón colonial del poder, de enfrentar el colonialismo interno. No en vano el mismo Quijano sostiene que "el actual movimiento indígena es la más definida señal de que la colonialidad del poder está en la más grave de sus crisis desde su constitución hace 500 años"9.

Son estas relaciones de dominación las que son puestas en cuestión, confrontadas directa y diversamente por los movimientos indígenas del continente y, por supuesto, como veremos, por el movimiento mapuche en Chile. En este marco, existe un enfrentamiento con distintas instancias y momentos de confrontación, con avances, y muchas derrotas, pero

\footnotetext{
${ }^{6}$ Pablo González Casanova, Colonialismo Interno (una redefinición). En La teoría marxista hoy Problemas y perspectivas Atilio A. Borón, Javier Amadeo y Sabrina González (compiladores) Buenos Aires: CLACSO, agosto 2006

${ }^{7}$ Boaventura de Sousa Santos, Epistemologías del sur, Revista Internacional de Filosofía Iberoamericana y Teoría Social, Zulia, 2011. P. 24

${ }^{8}$ Boaventura de Sousa Santos, Decolonizar el saber, reinventar el poder, 2013, Santiago, LOM.

9 Aníbal Quijano, "El Movimiento indígena y las cuestiones pendientes en América Latina", Argumentos UAM-X, México.
} 
se puede identificar logros interesantes del movimiento pese a la oposición sistemática desde el Estado chileno. Existen, por ejemplo, conceptos que a pesar de su argüible complejidad, se han asentado dentro del léxico común entre los militantes del movimiento mapuche. Al igual que en el resto de América latina, uno de los mayores logros ha sido el posicionamiento del concepto y la reclamación territorial y autonómica como central en el marco del conflicto, siendo esta "lucha por la autonomía uno de los principales discursos emanados desde el movimiento indígena a nivel continental convirtiéndose en una utopía de libertad"10. Territorio y autonomía representan expresiones discursivas contemporáneas con raíces profundas cultivadas en la relación de dominación y cimentadas en la construcción y reconstrucción decolonial indígena.

$\mathrm{Si}$ concordamos con quienes plantean el nacimiento del movimiento mapuche a inicios del siglo $\mathrm{XX}^{11}$, podremos ver cómo en su origen éste se focalizó básicamente en dos problemáticas fundamentales. Por una parte, en el contexto de una atmosfera de gran violencia hacia los mapuche, las primeras organizaciones se abocaron a la defensa ante los atropellos y abusos llevados a cabo con posterioridad a la invasión chilena ${ }^{12}$. Mientras que, por otra, se centraron también en la defensa y la lucha por la tierra, la oposición a la división de las tierras fue la principal bandera de lucha de las 2 principales organizaciones mapuche de comienzos del siglo XX la Sociedad Caupolicán y la Federación Araucana ${ }^{13}$. Las demandas de estas primeras orgánicas se centraron en la necesidad de obtener tierra para la sobrevivencia de la "raza", como se autoidentificaban por entonces los mapuche.

Desde la institucionalidad también se luchaba en este sentido, es así como podemos ver por ejemplo las palabras de Francisco Melivilu, primer mapuche electo diputado quien, desde el Congreso, ya en 1924 defendía de los abusos y despojo de tierras a los mapuche. "En mi hermosa provincia de Cautín, se han hecho escandalosas concesiones de tierras a ciertos señores que decían iban a colonizar y que no han colonizado; pero, en cambio se han quedado con los terrenos.... Pero lo más grave está en que este señor Silva Rivas que ocupa dos y tres veces más terrenos que los que le dieron unos malos títulos, de continuo está atropellando a los colonos nacionales y a los indígenas que viven en esos terrenos y tienen la desgracia de colindar o estar metidos en esas extensas propiedades. Y no solamente los molestan, sino que los atropellan de hecho con la fuerza de carabineros, les queman las casas y en seguida los mandan presos..."14

Más allá de detenernos en las similitudes con la actualidad o la diferencia clara y significativa que se establece en la declaración entre "nacionales" e indígenas, resulta interesante observar como ya desde comienzos del siglo XX se utiliza la institucionalidad como escenario de disputa en el marco del conflicto. La reclamación con respecto a la

${ }^{10}$ Fernando Pairican, Malon. La rebelión del movimiento mapuche, Santiago, pehuén, 2014, P. 109.

11 Víctor Naguil, De la Raza a la Nación, de la Tierra al País. Comunitarismo y Nacionalismo en el movimiento mapuche, 1910-2010, Tesis doctoral en Ciencia política, políticas públicas y relaciones internacionales, Universidad de Barcelona, 2016.

${ }^{12}$ Rolf Foerster y Sonia Montecino, Organizaciones, Líderes y Contiendas Mapuches. Chile: Centro Estudios de la Mujer, Santiago, 1988.

13 Jorge Pinto Rodriguez, El conflicto Estado-Pueblo Mapuche, 1900-1960, UNIVERSUM, N²7, Vol. 1, 2012. P. 183.

14 22.a Sesión ordinaria en 18 de junio de 1924 
recuperación de las tierras será central para el movimiento mapuche a lo largo de poco más de un siglo de historia, pudiéndose afirmar que representa la base del conflicto, que es "la demanda que sustenta las acciones reivindicativas de comunidades y organizaciones"15. Es durante la segunda mitad del siglo XX que surge la idea de territorio como concepto que excede lo que abarca la concepción de tierra, se empieza a insinuar en los setenta, pero adquiere su verdadera relevancia en los noventa ${ }^{16}$. El concepto de territorio indígena irrumpe no sólo diferenciando de hecho a indígenas de campesinos, sino además agregando componentes identitarios, consmovisionales, es decir, cimientos políticos y culturales a la demanda por autonomía.

Como afirma Ramón Maiz, territorio resulta un elemento discursivo que procede de la reformulación de su previa definición campesinista como tierra ${ }^{17}$. Sobre este basamento se desarrolla el concepto de territorio más en consonancia con la demanda autonómica, influyendo no solamente en los movimientos indígenas, sino también en instrumentos internacionales como el Convenio 169 de la OIT o la Declaración de derechos indígenas de la ONU. En lo concerniente al movimiento mapuche en tanto, observamos también este indudable cambio cualitativo que ha significado el paso de demandas principalmente de reconocimiento cultural, por tierras o económicas, por aquellas que reivindican las exigencias de tipo autonómicas. A las demandas por tierra o de corte economicistas, se agregan elementos de tipo nacional, de autodeterminación, de autonomía, además de demandas culturales. Se evoluciona de una exigencia por tierras usurpadas hacia una reclamación de tipo territorial y autonómica como derechos inalienables como pueblo. Concordando con Aparicio resulta determinante para la comprensión de las demandas autonómicas indígenas el salto del derecho a la tierra al derecho al territorio ${ }^{18}$.

Resulta importante señalar que no referimos a un tránsito lineal unívoco, muy por el contrario, la conformación reticular del movimiento mapuche permite ver una miríada de organizaciones con distintas reclamaciones, sin embargo, la relevancia y centralidad que ha adquirido para aquellas parte de lo que se ha caracterizado como el movimiento mapuche autonomista o de resistencia ${ }^{19}$ en las últimas décadas es innegable. Es en este contexto en el cual predominan los conceptos mencionados. Son el resultado de un proceso de construcción y reconstrucción identitaria cuya matriz principal, aunque no única, está en la cultura mapuche, destacándose además la irrefutable conexión y relación existente entre

\footnotetext{
15 González Karina, Eduardo Mella y Rodrigo Lillo "La política de la criminalización del movimiento mapuche bajo el sexenio de Lagos", P. 61. En El gobierno de Lagos, los pueblos indígenas y el "nuevo trato", José Aylwin y Nancy Yáñez (eds.), Santiago: LOM Ediciones.

${ }^{16}$ Gerardo Zúñiga, Los procesos de constitución de Territorios Indígenas en América Latina, Nueva Sociedad Nro. 153 enero-febrero 1998.

17 Ramón Maiz, Yawar Mayu: La construcción política de identidades indígenas en América Latina, En Salvador Martí y Josep Sanahuja, Etnicidad, Autonomía y gobernabilidad en América Latina, Ediciones Universidad de Salamanca, Salamanca, 2004, P. 359.

${ }^{18}$ Marco Aparicio, La construcción de la autonomía indígena: hacia el estado intercultural como nueva forma de estado. En Salvador Martí, Pueblos Indígenas y política en América Latina. El reconocimiento de sus derechos y el impacto de sus demandas a inicios del siglo XXI, Edicions Bellaterra, Barcelona, 2007.

${ }^{19}$ Tito Tricot, Autonomía, el movimiento mapuche de resistencia, Editorial Ceibo, Santiago, 2013.
} 
éstos. No siendo posible asumir las concepciones autonómicas o de autodeterminación sin la noción teórica y práctica del territorio, o este último sin plasmar su diferencia cualitativa con lo que se entiende por tierra.

La centralidad de lo territorial en las demandas mapuche y en el contexto del conflicto en concreto es innegable, pudiéndose encontrar en los planteamientos indígenas y la literatura según Víctor Toledo Llancaqueo al menos 5 nociones de lo que es territorio indígena, a saber: territorio como jurisdicción o una zona geográfica bajo control político indígena; como espacio geográfico de tierras a demarcar o restituir; como hábitat según la definición del convenio 169 de la OIT; como biodiversidad y conocimientos indígenas sobre la naturaleza y su expresión de derechos de propiedad intelectual; y por último, simbólicos e históricos, como una espacialidad socialmente construida vinculada a una identidad colectiva etnoterritorial ${ }^{20}$. Lo cierto es que en toda América Latina se pudo apreciar como en la década de los noventa aparecía el discurso de territorio como símbolo de "la gestión de recursos naturales, el autogobierno y el desarrollo de la identidad" 21.

Sea cual fuere la acepción utilizada, lo cierto es que es factible elucubrar, en base a la noción de territorio que emerge como marco interpretativo para los indígenas dos ideas concomitantes con esta centralidad conceptual. Por una parte, su ineludible vínculo ontológico con el concepto de autonomía indica que no es posible agenciar una efectiva libre determinación o autonomía sin territorio, y por otra, que el surgimiento del concepto de territorio se produce de manera sincrónica con la emergencia, la construcción y desarrollo del discurso identitario y cultural indígena como basamento colectivo de construcción movimental y de accionar colectivo.

Siguiendo a Tito Tricot es dable establecer que desde el movimiento mapuche cuando se hace referencia al territorio se estaría haciendo aludiendo a un espacio que "constituye un universo de dominación configurando un mapa de relaciones de poder, habitado por la memoria, la identidad, el idioma y la vida mapuche en su conjunto" 22 . Rememora pasado, pero construye futuro. Se asienta en cimientos mnemónicos, cosmovisionales y de cosmogonía; pero se agencia en el concepto y la praxis autonómicas, un constructo discursivo y dinámico que enmarca el actuar político de las organizaciones parte del movimiento. Indiscutiblemente el repertorio de acción colectiva más representativo en este sentido es lo que se ha calificado desde el movimiento mapuche como recuperación territorial, siendo en este sentido posible conceptualizar a la política también como espacio de disputa "territorial".

\footnotetext{
${ }^{20}$ Víctor Toledo Llancaqueo, Políticas indígenas y derechos territoriales en América Latina: 1990-2004 ¿Las fronteras indígenas de la globalización?, En Pablo Dávalos, Pueblos indígenas, estado y democracia, Buenos Aires, CLACSO, 2005

21 Álvaro Bello, Etnicidad y ciudadanía en América Latina. La acción colectiva de los pueblos indígenas. Naciones Unidas, Santiago, 2011.

22 Tito Tricot, La teluridad del movimiento mapuche autonomista; de la tierra al territorio, en Acción colectiva y movimientos sociales: Disputas y casos de estudio recientes, Editorial Punta Ángeles, Valparaíso, 2015 .
} 


\section{Recuperación territorial y política}

Una vez evidenciado el contexto endocolonial y la centralidad de la demanda territorial en el marco de los movimientos indígenas y del movimiento mapuche. Resulta necesario para fundamentar el argumento sostenido al comienzo, clarificar la manera en la cual desde el movimiento mapuche se ha agenciado en la praxis esta idea autonómica, pudiéndose aseverar que una de las formas más concretas y mediáticas ha sido mediante el repertorio de acción colectiva denominado como "recuperación territorial". Ejemplos de organizaciones tomando de facto tierras se pueden encontrar con anterioridad al periodo actual de democracia, específicamente durante la década de los setenta. Sin embargo, con la concepción de territorio como espacio de agenciamiento autonómico y poliédrico que hemos caracterizado, podemos recién observarlo surgir desde la década de los noventa.

La primera organización que adoptó luego de la transición ${ }^{23}$ como parte de sus repertorios de protesta las recuperaciones territoriales fue el Consejo de Todas las Tierras. Esta organización ya desde comienzos del nuevo régimen electo encabezado por Patricio Aylwin, sobre la base de 3 ideas centrales -protagonismo de las autoridades tradicionales y las comunidades, el derecho al autogobierno y la reclamación de territorio- ${ }^{24}$. Inician procesos de recuperación que impactarán mediáticamente el Chile transicional, convirtiendo al Consejo de Todas las Tierras en la organización más visible de aquellos años. Pese a esto, José Mariman señalaba un par de años después que en lo concreto "no ha recuperado un gramo de tierra a favor del pueblo mapuche"25. A pesar de esta afirmación, es posible afirmar que el Consejo de Todas las Tierras cooperó en poner en la agenda el tema mapuche y las recuperaciones territoriales que realizaron -tanto efectivas como simbólicas- fueron iniciáticas y sin duda relevantes en la movilización mapuche post dictadura.

Esta forma de actuar la retomaría unos años después la Coordinadora AraucoMalleco (CAM). Como han señalado varios autores los hechos acaecidos en Lumaco en 1997 se convertirán en una coyuntura crítica, un punto de inflexión para el movimiento mapuche, iniciándose acá un nuevo momento que entre otras cosas vería acciones más directas y confrontacionales. En este escenario la CAM al dejar de lado las recuperaciones simbólicas que se habían visto en los noventa, comenzando a actuar mediante "recuperaciones efectivas, que posteriormente la CAM denominó, control territorial, propusieron otro camino para lograr la autodeterminación" ${ }^{\text {"26 }}$. A esta nomenclatura se sumó también la idea que fue conocida como de "recuperación productiva", es decir, no sólo se recuperaba, sino además se la trabajaba, se explotaba el territorio recobrado. Para la Coordinadora Arauco Malleco era de medular importancia ocupar espacios territoriales y

\footnotetext{
${ }^{23}$ Como transición a la democracia se entiende en Chile al periodo inmediatamente posterior a finalizada la dictadura el 11 de marzo de 1990.

${ }^{24}$ Christian Martínez, Transición a la democracia, militancia y proyecto étnico. La fundación de la organización mapuche Consejo de Todas las Tierras (1978-1990), Estudios Sociológicos XXVII: 80, 2009.

25 José Mariman, La Organización mapuche Aukiñ Wallmapu Ngulam, en http://www.mapuche.info/mapuint/jmar2.htm

${ }^{26}$ Fernando Pairican Op. Cit.
} 
ejercer control sobre ellos desarrollando experiencias de autonomía territorial, experiencias que se dieron en distintos lugares del Wallmapu como Tirúa, Traiguen o Pantano, por nombrar algunas. Como afirmaban a un medio de comunicación por ese entonces, "Se puede mencionar que estas han sido y seguirán siendo recuperaciones productivas, es decir, experiencias donde las comunidades recuperan sus tierras para comenzar a sembrar arvejas, trigo, papas, para producir leña o realizar pastoreo de animales, entre otras actividades" 27. Como resume César Pineda, es factible identificar 4 ejes en cuanto a la forma de actuar de la CAM, a saber, la recuperación de tierras ancestrales; la defensa comunitaria de las tierras recuperadas; acciones directas sobre infraestructura de forestales o propietarios privados; e incipientes procesos de recuperaciones productivas ${ }^{28}$.

Estos métodos de actuar, resumidos en el control territorial que enarbolaba la CAM, se sustentan en la idea de que el problema no era simplemente de más o menos tierra, sino de la forma en que esa tierra se convertía efectivamente en territorio. No sólo hacerse del lugar de manera testimonial o simbólica, sino agenciar una apropiación en la praxis mediante su utilización y aprovechamiento. Se trata, entonces, de ejercer control territorial y establecer soberanía de hecho en las tierras recuperadas.

Por otra parte, el calificar desde el movimiento mapuche a estas acciones colectivas como "recuperaciones territoriales" no es baladí, responde a un posicionamiento político claro, concordante con el discurso autonómico medular del movimiento mapuche y con la idea de que se reapropia territorio que fue usurpado por la fuerza por parte del Estado de Chile, durante y a partir de la invasión del territorio mapuche a finales del siglo XIX. Como se ha indicado, la ocupación marca un hito en cuanto a la conflictiva relación entre el pueblo mapuche y el Estado de Chile, allí empiezan la mayoría de los actuales conflictos territoriales mapuches, existiendo la pérdida concreta de tierras y autonomía. Con este diagnóstico, como marco interpretativo transversal de la mayoría de las organizaciones mapuche que conforman el movimiento, es que la idea de "recuperar" lo arrebatado comienza a dar sentido tanto a las recuperaciones como al control territorial sobre estas.

Pero ¿cómo se relaciona esto con el accionar desde el movimiento mapuche en política mediante instituciones o convencional? Si la política convencional se entiende como acciones en sintonía con las normas y valores de la sociedad, entre la que se encuentran el votar, participar en campañas electorales, contactar con cargos públicos o con medios de comunicación, asociacionismo, afiliación política, entre otras ${ }^{29}$ ¿Qué tiene que ver esto con la recuperación territorial?

Al considerarse territorio un concepto más amplio y significativo que la noción más simple y unívoca de tierra. El recuperar territorio tiene implicaciones y consecuencias de mayor envergadura y por cierto de interés para el movimiento mapuche. La recuperación territorial de facto se inserta en el terreno de lo político pues, al menos a nivel micro, intenta establecer autonomía en la práctica. Esta praxis política repercute en represión

\footnotetext{
27 Tito Tricot. La lucha del Pueblo Mapuche, Ilwen Ediciones, Valparaíso, 2006, P. 303.

${ }^{28}$ Cesar Pineda, Mapuche resistiendo al capital y al estado. El caso de la Coordinadora Arauco Malleco en Chile, Latinoamérica. Revista de Estudios Latinoamericanos, Volumen 59, 2014, P. 59.

${ }^{29}$ Verge, T. (2014) Comportamiento político en Lois, M. y Alonso, A. "Ciencia política con perspectiva de género", Ediciones akal, España,
} 
desde el Estado por tanto no sólo subvierte el espacio recuperado, sino que es un acto que confronta la concepción omnipresente de propiedad privada neoliberal y el monopolio del poder estatal.

Lo anterior es precisamente lo que nos compele a sostener que la política convencional es un territorio a recuperar. La capacidad de incidencia al actuar en este contexto potencialmente aumentaría, no sólo por estar en puestos de representación desde los cuales se puede posicionar ideas o luchar por reformas o políticas públicas, sino porque la coacción y represión de parte del Estado no podría manifestarse como en las comunidades sin atentar contra el orden democrático. O simplemente parafraseando a Pablo Dávalos al referirse a los movimientos indígenas latinoamericanos, entrega la posibilidad de provocar fisuras en esa caja de acero de la modernidad occidental ${ }^{30}$.

El escenario de política convencional es un espacio en el que los mapuche se han movido casi desde el final mismo de la invasión, creando organizaciones propias, pero también actuando en los marcos del sistema de partidos y político chilenos, siendo posible argüir que hasta la dictadura militar siempre se explotó esta alternativa con resultados sin duda disimiles, pero también en ocasiones con logros interesantes para el movimiento mapuche. Desde el inicio de la transición es menor su utilización y la presencia de mapuches en puestos de representación o designados desde el gobierno central, sigue siendo en general relegados a puestos de segundo orden, ergo la necesidad de recuperar y potenciar este espacio de participación.

Antes de mostrar en el acápite siguiente la manera en la cual esta participación convencional ha tomado forma, es dable plantear dos ideas en consonancia con lo expuesto. Por un lado, que la recuperación de la política es factible de ser interpretada también como una expresión contemporánea de la realidad mapuche, donde gran parte de su población está ubicada en urbes y a los cuales la recuperación de territorios ancestrales les es más ajena. En consecuencia, la recuperación del territorio político convencional otorga mayores posibilidades de identificación y cercanía. Por otra parte, es que se traslada la partida contrahegemonica - en términos gramscianos-a otra de las caras del poliedro. Ya no sólo se actúa en un marco contencioso, sino además proactivo y empoderado, probablemente aún no en igualdad de condiciones o descolonizado, pero al menos jugando en la misma cancha. Como veremos a continuación, intentos en esta dirección se han evidenciado durante la historia de la relación entre el Estado de Chile y los mapuche.

\section{Repaso histórico pre-dictadura}

Concentrando el foco en la participación mapuche mediante herramientas más desde lo institucional y convencional, una mirada retrospectiva, nos permite ver el surgimiento de organizaciones mapuche casi inmediatamente con posterioridad a la invasión militar chilena. Finalizada la conquista de territorios mapuche por parte del estado a fines del siglo XIX, los mapuche desde el comienzo intentaron participar de la vida política chilena,

\footnotetext{
${ }^{30}$ Pablo Dávalos, Movimiento indígena ecuatoriano: construcción política y epistémica. En libro: Cultura, política y sociedad Perspectivas latinoamericanas. Daniel Mato. CLACSO, Consejo Latinoamericano de Ciencias Sociales, Ciudad Autónoma de Buenos Aires, Argentina. 2005.
} 
tratando de influir o ser parte de las decisiones que les concernían. No es intención de este artículo ahondar en tiempos tan pretéritos, tan solo reiterar a modo de contextualización que las primeras organizaciones en los albores del siglo XX tuvieron como objetivo primordial defender y abogar por los mapuche en un contexto de desprotección ${ }^{31}$. La participación en política ha sobrepasado ya desde entonces lo meramente no convencional, intentando lograr entre otras formas, representatividad dentro del sistema político chileno, ya sea como militantes de partidos políticos o como independientes.

En cuanto a la participación electoral, los líderes mapuche "tuvieron temprana conciencia del poder de la política para lograr la solución de los problemas de su pueblo y manifestaron desde el comienzo inquietud por alcanzar una representación indígena en el parlamento"32. Es así como ya en 1914 la Sociedad Caupolicán incursionaba en la búsqueda de representación política participando en las elecciones. El año 1924, Francisco Melivilu Henríquez fue elegido diputado ante el Congreso de Chile por el Partido Demócrata, siendo el primero de los 9 parlamentarios de ascendencia mapuche en la historia de la democracia chilena. El último mapuche en el congreso fue el demócrata cristiano Francisco Huenchumilla, quien fue representante durante 3 periodos ${ }^{33}$.

La etiología de esta presencia constante en el sistema político chileno la podemos encontrar en las palabras de Venancio Coñuepan, histórico líder mapuche del siglo XX, quien ya a principios de la década de los 30 señalaba que: "esta raza no ha tenido representación en el parlamento y necesita, imperiosamente, para la solución de sus problemas, tener por lo menos un quinto de representantes que sean aborígenes, que conozcan sus problema, que los sientan hondamente y que nazcan del seno de sus congresos, a fin de que lleven el verdadero sentir de sus representados" 34 .

La dictadura provocó un gran retroceso para los mapuche, no sólo territorialmente, sino también en cuanto a participación y desarrollo del movimiento y organizaciones autónomas. Además, se puede argumentar que en general en los años ochenta se dio una clara supeditación de cualquier tipo de reivindicación política del país a la lucha por el retorno democrático. Existió movilización, organización y desarrollo de un discurso autonómico mapuche en este periodo, sin embargo, la relevancia de este fue siempre en el marco de la lucha por el retorno de la democracia. Admapu fue la organización más destacada en este contexto, pero también ofrece la posibilidad de ver las tensiones entre este discurso más autonomista y la lealtad de sus miembros con los partidos políticos

\footnotetext{
${ }^{31}$ José Ancan, Venancio Coñuepan, Editorial Universidad de Santiago de Chile, Santiago, 2005.

32 Rolf Foerster y Sonia Montecino, Organizaciones, Líderes y Contiendas Mapuches. Chile: Centro Estudios de la Mujer, 1988, P, 14.

${ }^{33}$ Los diputados de ascendencia mapuche son: Francisco Melivilu por el Partido Demócrata (1924 -1927 , 1926-1930, 1930-1934); Manuel Manquilef por el Partido Liberal Democrático (1926-1930, 1930-1932); Arturo Huenchullan Partido Democrático (1933-1937); Esteban Romero Partido Nacional Cristiano (19531957); José Cayupi Partido Nacional Cristiano (1953-1957); Venancio Coñuepan Partido Conservador Unido (1945-1949, 1949-1953, 1965-1968); Manuel Rodríguez Wenumañ Partido Demócrata Cristiano (19651969); Rosendo Huenumán Partido Comunista (1973-1977); y Francisco Huenchumilla, Partido Demócrata Cristiano (1990-1994, 1994-1998, 1998-2002).

${ }^{34}$ Rolf Foerster y Sonia Montecino, Op Cit. P. 88.
} 
chilenos $^{35}$. Complementando lo anterior, Caniuqueo sostiene que las relaciones clientelares fueron la base de la política para con los mapuche de los años 80, lo que no evitó la búsqueda de un camino propio, comenzando a gestarse ideas y pensamientos con mayor énfasis en la construcción de un proyecto autónomo mapuche ${ }^{36}$.

En el periodo posterior a la dictadura militar, la participación de los mapuche se efectuó principalmente de forma no convencional, siendo esto debidamente estudiado desde diferentes perspectivas, disciplinas y autores. A continuación, lo que se pretende es abordar aquellas formas de participación política más convencionales de los mapuche en los últimos 2 lustros.

\section{La política convencional como recuperación de territorio}

Como Pacto de Nueva Imperial se conoce el acuerdo realizado entre algunas organizaciones indígenas y el entonces candidato a la presidencia de la República de Chile Patricio Aylwin, y que se llevó a cabo en las postrimerías de la dictadura. Este tenía como objeto que los mapuche y demás indígenas del país lo apoyaran en las elecciones venideras; el acuerdo estipulaba que el nuevo gobierno democrático, a cambio de dicho apoyo, se comprometía a reformar la constitución del país y reconocer a los pueblos indígenas, además de promulgar una nueva legislación indígena que contaría con la participación de estos en su elaboración. Una vez iniciado el gobierno de Patricio Aylwin este decreta en mayo de 1990 la creación de una Comisión Especial para los Pueblos Indígenas (CEPI) que se encargaría de encabezar el proceso de redacción del proyecto de la nueva ley indígena. Nueva Imperial sentó las bases de lo que sería la creación del consenso entre Estado de Chile e indígenas para la nueva democracia, sin embargo, luego del trabajo llevado a cabo por la CEPI, el proyecto sufrió numerosos y sustantivos cambios en los casi 3 años que estuvo en trámite en congreso. Promulgándose finalmente en 1993, la Ley Indígena $\mathrm{N}^{\circ} 19.253$ es hasta el día de hoy el marco legislativo principal de los pueblos indígenas del país.

El Acuerdo de Nueva Imperial despertó grandes expectativas que se diluyeron rápidamente ${ }^{37}$. Pese al descontento con el producto final, este proceso fue un momento en el cual miembros de diferentes pueblos originarios del país se la jugaron por entero mediante la vía institucional ${ }^{38}$. Sin embargo, el incumplimiento de lo pactado en Nueva Imperial y el desencanto con la Ley Indígena son un punto de inflexión, un símbolo que marca el comienzo de la deriva del movimiento mapuche desde la política convencional, las instituciones e incluso de los partidos chilenos. El cenit cúlmine y autonómico, podemos

\footnotetext{
${ }^{35}$ Martínez Neira, Christian, y Patricia Rodríguez. 2015. "Partisan Participation and Ethnic Autonomy: The Case of the Mapuche Organisation Admapu, in Chile". Journal of Latin American Studies FirstView (octubre): 1-28.

36 Sergio Caniuqueo, Dictadura y pueblo mapuche 1973 a 1978 reconfiguración del colonialismo chileno, Revista de Historia Social y de las Mentalidades Volumen 17, No 1, 2013.

${ }^{37}$ Jorge Pinto Rodriguez, "Pueblo mapuche, 1810-2015. Dos siglos de lucha por justicia, reconocimiento y respeto” P. 99. En Nueva constitución y pueblos indígenas, Editorial pehuén, Santiago, 2016.

${ }^{38}$ José Bengoa, Mapuche, colonos y el Estado Nacional, Editorial Catalonia, Santiago, 2014
} 
señalar, fueron los acontecimientos de Lumaco en 1997. Al cerrarse o dejar de confiar en las instancias institucionales, se optó desde el movimiento mapuche por otros repertorios de acción colectiva más contenciosos.

A pesar del ostensible predominio de lo movimental y la actuación política no convencional, la utilización de medios institucionales y de política convencional nunca desaparecieron por completo, pero sin lugar a dudas se encontraban relegados a un plano secundario. Por ende, el espacio convencional se convierte en un territorio a recuperar y desde el cual posicionar la demanda autonómica. Lo planteado no resulta nada sencillo en el contexto chileno. Si observamos por ejemplo los cargos designados -cargos de cierta relevancia en términos de autoridad- que han detentado personeros de ascendencia mapuche desde la transición, su descripción no requiere demasiado espacio en este artículo, siendo posible aseverar que este corresponde a su vez a un reflejo más de la condición endocolonial referenciada en un comienzo.

Un repaso ${ }^{39}$ de autoridades designadas en el país desde 1990 hasta hoy evidencia que en este cuarto de siglo ha habido un ministro -el mismo Francisco Huenchumilla-; tres subsecretarios, un embajador; y dos intendentes. De hecho, los trabajos que analizan a la elite política no incluyen el tema de la ascendencia indígena como un factor ${ }^{40}$. La presencia mapuche en cargos de importancia es marginal, no obstante representar entre un $4 \%$ y un $10 \%$ de la población ${ }^{41}$.

La recuperación implica una acción de tipo proactiva, por tanto, lo anterior, es decir los cargos designados, para este caso concreto interesan menos, sin embargo, sirven para ejemplificar la dificultad de acceso a cargos de importancia de quienes tienen ascendencia mapuche. De la misma forma, es necesario agregar que tampoco interesan en este artículo los planes que se elaboran desde cada gobierno para "solucionar" el "problema" o el "conflicto" o como se le denomina ahora la "violencia" en la Araucanía 42 . Lo que se pretende es destacar la "recuperación" del espacio de política convencional como estrategia

\footnotetext{
${ }^{39} \mathrm{La}$ manera en la cual hemos identificado la ascendencia se remite simplemente a que uno de los apellidos de la autoridad sea de ascendencia mapuche. Evidentemente esto no es de una rigurosidad infalible, tanto porque este puede tener el apellido y no existir autoidentificación. Así también, y producto de la relación de dominación planteada, puede no tener el apellido, pero sí ser de ascendencia mapuche.

${ }^{40}$ Ver Alejandro Olivares et al DAAPGE, año 15, $\mathrm{N}^{\circ}$ 24, 2015, pp. 7-31. "Los gabinetes ministeriales en la democracia chilena pos 1990: un caso de estabilidad, continuidad histórica y negociación inter-partidaria Cambios de gabinete y supervivencia de los ministros en Chile durante los gobiernos de la Concertación (1990-2010)", 2015.

41 Según el Censo de 1992, existían en Chile un total de 927.060 mapuche de más de 14 años, esto representaría el $8,7 \%$ de la población total del país. De añadirse a estos resultados la población faltante, es decir los menores de 14 años, la población mapuche se estimaría cercana al 11\%. Según los datos recogidos en el Censo de 2002 un 4,6\% de la población total del país correspondería a, según la terminología utilizada en el censo, "grupos étnicos", siendo este porcentaje equivalente a 692.192 personas. De éstas, el $87 \%$ corresponde a mapuche, lo cual en cifras absolutas se traduce en 604.349 personas, lo que equivale al 3,84\% de la población total del país. No hace falta decir que existe una diferencia sustancial entre los resultados de ambos censos. El país se encuentra en proceso de corrección de los datos del censo de 2012.

${ }^{42}$ Las comillas son para destacar la diversidad de adjetivos que se han utilizado para caracterizar la situación en La Araucanía. Nos referimos como soluciones a mesas de diálogo, Nuevo Trato, Plan Araucanía, entre otras.
} 
del movimiento mapuche. Desde esta óptica, recordando la dinámica organizacional mapuche, observamos una miríada de organizaciones e instancias de participación que han surgido desde 1990 en adelante como aquellas canalizadas a través del Estado y la Corporación Nacional de Desarrollo Indígena (CONADI), la participación permanente y creciente en elecciones municipales de candidatos de ascendencia mapuche, la creación de la Asociación de Municipalidades con Alcaldes Mapuche (AMCAM), la utilización de las herramientas que ofrece el derecho nacional e internacional, el largo y dificultoso camino emprendido por el partido político mapuche Wallmapuwen o la dicotomía tradición/novedad de la Corporación de Profesionales Mapuche (ENAMA).

Todas estas dan cuenta de modalidades diversas de aproximarse a lo político desde lo convencional, de un actuar proactivo y muchas veces con un horizonte o praxis autonómicas. No siempre, es cierto, pero se podría sostener que muchas de estas orgánicas y actuaciones emanadas de estas son expresiones tangibles de la recuperación del territorio político convencional para el movimiento y el pueblo mapuche. Es efectivo que se han realizado argumentaciones contrarias, sosteniendo que estas son manifestaciones autorizadas, que representan ejemplos de lo que en el marco del multiculturalismo neoliberal es lo permitido, planteando la inviabilidad de la autodeterminación en este marco y que los ejemplos de representación mapuche en el contexto de la política chilena "más que tolerancia o empoderamiento, dentro del sistema chileno demuestran genuflexión hacia la élite dominante. Antes del diálogo con esta, son las diferentes posturas autodeterministas mapuche las que deben convergir en una propuesta nacional de representatividad previamente discutida, conversada, reposada"43.

Sin embargo, como se ha evidenciado, lo convencional es consustancial al movimiento, siendo estas expresiones políticas una estrategia, un repertorio más. Negar la relevancia de la recuperación del territorio político convencional implicaría que en el contexto mapuche lo convencional y lo movimental serían formas de participación desvinculadas. Por el contario, están intrínsecamente interconectados, existiendo trabajo conjunto, campañas políticas similares, marcos interpretativos coincidentes, y multi militancias también interconectadas. Acá concordamos con Pairican cuando plantea que este movimiento se caracterizó por dos lineamientos políticos: uno más político institucional y otro más rupturista, pero ambos con el objetivo de luchar por la autodeterminación ${ }^{44}$.

El optar por la política convencional es una forma más para aproximarse a una praxis política autonómica que sin duda se aleja de la violencia, mas no de la confrontación o lo contencioso. En un contexto de consolidación de la democracia electoral como forma predominante de organización de la vida política en el país con posterioridad a la transición, la opción por la participación en política convencional se convierte en un territorio a recuperar, existiendo manifestaciones de esto evidenciables desde 1990 en adelante. Así encontramos, por ejemplo, la persistente participación de candidatos mapuche en las elecciones municipales llevadas a cabo en el país. A nivel de elecciones locales no se replicaba el modelo electoral binominal que predominaba en el contexto nacional, lo cual

\footnotetext{
${ }^{43}$ Artículo de Jorge Aillapan http://m.elmostrador.cl/noticias/opinion/2016/11/29/el-autogobierno-mapuche/

${ }^{44}$ Fernando Pairican, Malon. La rebelión del movimiento mapuche, Santiago, pehuén, 2014.
} 
implicaría una ventana de oportunidad para la aparición de actores o partidos que representen otros intereses a los manifestados en el sistema de partidos nacional. De alguna manera lo local se convierte en uno de los pocos espacios que, pese a la dificultad de acceso, ofrece cercanía al poder. La recuperación de este "territorio" no es ni fácil, ni extendido cuantitativamente, sin embargo, se puede mantener que desde el final de la dictadura el municipio se convirtió en un "espacio político a disputar, como un espacio donde la población mapuche, antes marginada, comenzó a desarrollar estrategias que le permitieran viabilizar su participación en el poder local, incorporando en ello reivindicaciones indígenas" 45 .

Esto último es primordial, pues se pretende agenciar poder, o, en otras palabras, desde la institucionalidad manufacturar un contrapoder, posición desde la cual se puedan posicionar ideas, conceptos y praxis autonómica mapuche, un "nicho de poder administrado bien para poder influir en el movimiento indígena y en las políticas públicas a nivel local" 46 Es decir, producir un doble efecto desde este contrapoder, toda vez que se sostiene sobre una idea de identidad mapuche que remite al pasado, pero que construye alternativas concretas, elaboradas éstas en consistencia con ideas autonómicas.

Esta producción de sentido emana fundamentalmente desde lo movimental, pero su potencial de influir desde lo convencional ofrece a su vez una capacidad de producción simbólica, discursiva y de políticas públicas que son sin duda complementarias y necesarias. O en palabras de de Sousa Santos, se utilizan de manera contrahegemónica instrumentos hegemónicos ${ }^{47}$. Un ejemplo concreto de esto puede ser por ejemplo la oficialización del mapudungun junto al castellano como lengua oficial en la comuna de Galvarino el año 2013, municipalidad dirigida entonces por el alcalde mapuche, Jorge Huaiquil. Lo anterior no estuvo exento de resistencias, pero un dictamen de la Contraloría el año siguiente ratificaba la ordenanza municipal señalando que "la municipalidad de Galvarino cuenta con atribuciones para regular la inclusión del idioma mapuzugun como lengua oficial, junto al castellano, en el ámbito de las actividades municipales, lo cual provee a satisfacer las necesidades de la comunidad local, en condiciones de igualdad atendida la composición étnica de esa comuna, como asimismo, al cumplimiento de sus funciones inherentes al desarrollo social y cultural de ésta última" ${ }^{4}$. La oficialización del mapudungun es una reclamación transversal de muchas organizaciones mapuche de la Araucanía cuya visibilización más conocida es la marcha que se realiza cada febrero en Temuco. Pese a esto, sigue siendo una aspiración. Por su parte, la experiencia de Galvarino demuestra en la práctica la relevancia la recuperación del territorio político convencional.

\footnotetext{
${ }^{45}$ Claudio Espinoza, Municipio, procesos electorales y etnicidad. Trans-formaciones en la distribución del poder político municipal, P. 255. En Pueblos indígenas, Estados Nacionales y fronteras. Tensiones y paradojas de los procesos de transición Contemporáneos en América Latina, Buenos Aires, Editorial de la Facultad de Filosofía y Letras.

46 Entrevista a Adolfo Millabur, Alcalde mapuche de Tirua, citado en Natalia Caniguan, Trayectorias políticas. Historias de vida de alcaldes mapuche, Santiago, RiL editores, 2015.

${ }^{47}$ Boaventura de Sousa Santos, Decolonizar el saber, reinventar el poder, 2013, Santiago, LOM, P.18

48 Dictamen 045010N14 del 20 de junio de 2014, controlaría General de la República. División de Coordinación e Información Jurídica.
} 
Como se ha observa, el contexto endocolonial no favorece el posicionamiento en puestos de poder de los mapuche, sin embargo, obliterar al movimiento mapuche de aquellas acciones colectivas más convencionales, no sólo cercena una posibilidad de decolonización desde el poder, sino que invisibiliza a una parte relevante del movimiento. En este mismo sentido encontramos otras experiencias del movimiento mapuche y que han optado por la recuperación del territorio político.

Con la opción por la lucha por el poder local y electoral, nació también hace poco más de una década el partido político mapuche Wallmapuwen, organización que luego de muchas complicaciones logró finalmente legalizarse en la región de la Araucanía durante $2016^{49}$. Pese a esta tardía regularización ante la institucionalidad del Estado, Wallmapuwen lleva desde el año 2005 siendo parte de la vida política regional. Ya desde su declaración de principios se plantean entre otras cosas la elaboración de un estatuto autonómico, la reconstrucción nacional del Wallmapu (país mapuche) y el acceso al poder político como horizonte, y afirmando, además, la necesidad de incluir a mapuche y no mapuche ${ }^{50}$ como parte de este proyecto. Desde 2008 que participan en elecciones, pero hasta 2016 esta participación se dio como independientes o apoyando a algún candidato en particular que se presentara como representante de un partido chileno autorizado para participar en las elecciones. Las últimas municipales de 2016 marcaron un hito, se presentaron por primera vez a las elecciones como partido político legalmente constituido en la región de la Araucanía. Presentando el partido 33 candidatos en 10 comunas, además de una candidatura a alcalde en Puerto Saavedra. Lo anterior adquiere relevancia, más que por los resultados (sólo obtuvieron una concejalía ${ }^{51}$ ), porque es la primera vez en la historia de Chile que concurre a cualquier elección un partido político mapuche.

Propuestas autonómicas concretas, posicionamiento del discurso, la praxis autónoma y la clara vocación de acceso al poder son manifestaciones de la decidida intención de recuperar territorio político convencional. La eficiencia o impacto del partido es probablemente debatible, sin embargo, su configuración y consolidación como un actor político colectivo en la Araucanía, resulta innegable, siendo expresión de lo que Pairican llama la "vía política" por la disputa de la autodeterminación. Por último, sin directamente ser parte de lo que se ha identificado como esta vía política, resulta interesante observar también las acciones políticas convencionales implementadas por la Corporación de Profesionales Mapuche, ENAMA. Creada en el año 2011, esta institución no ha estado exenta de polémicas en el seno del movimiento mapuche precisamente por su ámbito de acción, es decir, la actuación a nivel de política institucional y convencional. Sin optar por la participación en elecciones, sí han optado por el camino de intentar influir en las políticas públicas que conciernen a los mapuche en la esfera institucional.

Se identifican como una institución integrada por destacados profesionales mapuche de diversos ámbitos y como deudores de la tradición institucional de otras organizaciones mapuche, especialmente de la Corporación Araucana que lideró Venancio Coñuepan en la segunda mitad del siglo XX. Esto último es lo que nos ha llevado a calificarlo más arriba

${ }^{49}$ Wallmapuwen volvió a perder su categoría de partido político legal a finales de abril de 2017

${ }^{50}$ Declaración de Principios. El partido al que aspiramos. Comisión política, Wallmapuwen, octubre de 2005

51 Sara Huenchupil salió electa concejala en la comuna de Galvarino 
como representantes de una dicotomía tradición/novedad, toda vez que continúan en la senda del trabajo político llevado a cabo por décadas. Pero, además, innovan pues desde la transición no había existido una organización relevante de este tipo que desde las plataformas ofrecidas por la institucionalidad chilena se plantea buscar "diversas iniciativas y proyectos, impulsar el desarrollo integral mapuche, incidir en el debate público y contribuir con sus acciones a la construcción del Chile Plurinacional del Siglo XXI", propiciando "la articulación entre los distintos actores públicos y privados, a fin de generar redes y acuerdos, detectar oportunidades y contribuir con ello al ejercicio del derecho a la autodeterminación mapuche, consagrado desde 2007 en la Declaración Universal de Derechos de los Pueblos Indígenas de la ONU"52.

La vida de ENAMA es corta, pero fructífera pudiendo apreciarse a lo largo de ésta la realización de encuentros nacionales (Futa Trawun), organización de seminarios, diplomados, cursos, entre otros. Esta corporación lentamente se ha posicionado como actor político. Desde su aparición mediática, y especialmente a partir de sus macro encuentros anuales en la ciudad de Temuco, ENAMA, paulatinamente ha adquirido relevancia, siendo por ejemplo convocados por el gobierno de Michelle Bachelet en julio de 2016 a ser parte de la mesa de dialogo conocida como Comisión Asesora Presidencial de La Araucanía.

Todas las expresiones de acción colectiva y organizaciones reseñadas corresponden a formas de participación política que -pese a plantear ideas que muchas veces se confrontan directamente con el statu quo endocolonial dominante- son realizadas mediante formas convencionales, en general aceptadas por la sociedad. Representan ejemplos evidenciables post pacto de Nueva Imperial de las distintas formas en las cuales se busca desde algunas organizaciones del movimiento mapuche el recuperar el territorio político convencional.

\section{Consideraciones finales}

A comienzos de la década de los 90 el mexicano Bonfil Batalla afirmaba con respecto a los pueblos indígenas que sus historias que no son todavía historia, no lo eran pues estaban por escribirse, habiendo sido hasta entonces narradas desde una posición colonial; y no lo eran tampoco pues no están concluidas, están abiertas, en proceso ${ }^{53}$. En Chile es posible una argumentación análoga. Sin embargo, en términos políticos afirmar en el contexto mapuche que existe una política que no es todavía política, nos plantea ante una aporía. Pues pese a, y en correlación con la relación de dominación endocolonial, se ha podido visibilizar dos fenómenos concomitantes.

Por una parte, la efectiva relegación de los mapuche a un segundo plano de la política institucional, no teniendo representantes, partido político propio por mucho tiempo o inclusive autoridades en puestos de primer orden. Es decir, la existencia, pero el evidente confinamiento de presencia mapuche en la política chilena del siglo $\mathrm{XX}$, y por sobre todo con posterioridad a la transición a la democracia.

\footnotetext{
52 http://www.enama.cl/enama/

${ }^{53}$ Guillermo Bonfil Batalla, "Historias que no son todavía historia”. En Carlos Pereyra Historias ¿̨para qué?, México, Siglo XXI Editores, 1980.
} 
Pero a su vez, se observa la incuestionable constancia en participación política convencional y no convencional- de los mapuche desde finalizada la invasión de su territorio, que pese a sufrir un decaimiento en cuanto a lo institucional después de 1990, ha mantenido una presencia creciente con diversas organizaciones optando por la política convencional y las instituciones como escenario para agenciar sus demandas. En síntesis, pese a no haber existido partido (hasta 2016) u mayor presencia en las instituciones, sí existe política mapuche.

Como se ha visto, de ninguna manera el separar ambas formas de actuación política debe resultar en una analogía vernácula de reforma o revolución, sino que son formas complementarias de actuación en el movimiento mapuche, no son dicotómicas, muy por el contrario, pese a por momentos poder enfrentarse las diferentes organizaciones por modalidades de esta participación. Es posible afirmar que la proliferación de repertorios de acción colectiva de diversa índole no es más que una respuesta concordante con la búsqueda de expresión y representación política propia en un contexto de dominación endocolonial. Dicho de otra manera, puede aseverarse que es un efecto no deseado de la constricción, de la violencia y por cierto de la inexistencia de espacios y reconocimientos políticos formales.

En este marco se inscribe la premisa que ha guiado este artículo, a saber, el concepto de territorio como espacio poliédrico, con manifestaciones múltiples que no se circunscribe sólo a un lugar físico y que es por esencia, política. Siendo la recuperación de este fundamental en la reclamación autonómica del movimiento mapuche, y la recuperación de la presencia en política institucional parte integral e inseparable de esta. En la comunidad imaginada chilena no se incluye lo indígena o mapuche y en la democracia establecida luego de la dictadura tampoco. Aunque el pacto de Nueva Imperial representa una inflexión en este aspecto. Es así como la emergencia de la recuperación territorial como herramienta de praxis política autonómica asoma en el escenario político especialmente del sur de Chile. Estas recuperaciones simbólicas, efectivas, productivas o de control territorial inevitablemente se confrontan en la práctica y epistémicamente con el modelo y la propiedad neoliberal. De esta colisión derivan la represión y el conflicto en la últimas dos décadas. En este contexto el recuperar el territorio político convencional o la participación mediante formas políticas aceptadas se convierte en un repertorio más para el movimiento mapuche, siendo una herramienta interesante a la hora de enfrentar la relación de colonialismo interno, planteando alternativas desde el poder y las instituciones. La política convencional es una de las aristas a recuperar del territorio que hemos calificado de poliédrico, teniendo este, así como otras formas de actuación política un potencial descolonizador o de confrontación a la colonialidad del poder que mencionaba Quijano.

Como se mencionó con anterioridad, las críticas pueden ser muchas, pero pareciera posible plantear que en un contexto endocolonial en el cual los pueblos indígenas no tienen representación y el pueblo mapuche sufre los embates del racismo y la violencia, posicionarse en términos de suma cero no contribuye al ideal democrático de inclusión para el Chile del siglo XXI. Hace décadas, Fanon señalaba que "en las colonias la infraestructura 
es igualmente una superestructura"54, pudiéndose intuir a partir de aquí la necesidad de no menoscabar ninguna forma de lucha del colonizado. Esto lo entendieron desde el inicio los viejos dirigentes mapuche del siglo pasado que lucharon desde distintas esferas para recuperar el territorio político convencional y que luego de una baja presencia en este ámbito a partir de la transición de 1990, vuelve a posicionarse como escenario legítimo de disputa. Esta arena política es consustancial al movimiento mapuche desde sus inicios y representa, junto a las diversas manifestaciones movimentales visibles en el marco del conflicto, una cara más de la lucha por recuperación territorial, por la autonomía como pueblo en un contexto ya centenario de colonialismo interno.

\section{Bibliografía}

José Ancan (2010) Venancio Coñuepan, Editorial Universidad de Santiago de Chile, Santiago.

Marco Aparicio (2007), "La construcción de la autonomía indígena: hacia el estado intercultural como nueva forma de estado". En Salvador Martí, Pueblos Indígenas y política en América Latina. El reconocimiento de sus derechos y el impacto de sus demandas a inicios del siglo XXI, Edicions Bellaterra, Barcelona.

Bello, Álvaro (2004) Etnicidad y ciudadanía en América Latina. La acción colectiva de los pueblos indígenas. Naciones Unidas, Santiago de Chile.

Bengoa, José. (1999). Historia de un conflicto: El estado y los mapuches en el siglo XX. Santiago Chile: Planeta/Ariel.

(2000). La emergencia indígena en América Latina. Fondo de Cultura Económica.

(2014). Mapuche, colonos y el Estado Nacional. Editorial Catalonia, Chile.

Caniguan, Natalia. (2015). Trayectorias políticas. RiL editores, Santiago.

Caniuqueo, Sergio. (2013) "Dictadura y pueblo mapuche 1973 A 1978 reconfiguración del colonialismo chileno", Revista de Historia Social y de las Mentalidades Volumen 17, No 1, 2013.

........(2009) "Particularidades en la instauración del colonialismo chileno en el Gulu Mapu, 18841950. Subordinación, alianzas y complicidades". En Las disputas por la etnicidad en América Latina. Movilizaciones indígenas en Chiapas y la Araucanía.

Espinoza, Claudio. (2014). "Municipio, procesos electorales y etnicidad. Trans- formaciones en la distribución del poder político municipal". En Pueblos indígenas, Estados Nacionales y fronteras. Tensiones y paradojas de los procesos de transición Contemporáneos en América Latina.

González Casanova, Pablo. (2006). El Colonialismo interno. Una redefinición.

http://bibliotecavirtual.clacso.org.ar/ar/libros/campus/marxis/P4C2Casanova.pdf

González Karina, Eduardo Mella y Rodrigo Lillo "La política de la criminalización del movimiento mapuche bajo el sexenio de Lagos". En El gobierno de Lagos, los pueblos indígenas y el "nuevo trato”, José Aylwin y Nancy Yañez (eds.), Santiago: LOM Ediciones.

Fanon, Frantz. (2011) Los condenados de la tierra, Fondo de Cultura Económica, México

Foerster, R., \& Montecino, S. (1988). Organizaciones, Líderes y Contiendas Mapuches. Chile: Centro Estudios de la Mujer.

Maiz, Ramón (2004) "Yawar Mayu: La construcción política de identidades indígenas en América Latina", En Salvador Martí y Josep Sanahuja, Etnicidad, Autonomía y gobernabilidad en América Latina, Ediciones Universidad de Salamanca, Salamanca.

\footnotetext{
${ }^{54}$ Frantz Fanon, Los condenados de la tierra, Fondo de Cultura Económica, México, P. 34.
} 
Marimán, José. (2012). Autodeterminación. Ideas políticas Mapuche en el albor del Siglo XXI. Chile: LOM Ediciones.

(1995) "La Organización mapuche Aukiñ Wallmapu Ngulam", en

http://www.mapuche.info/mapuint/jmar2.htm

Marimán, Pablo. (2006). "Los mapuche antes de la conquista militar chileno-argentina". En ¡...Escucha winka...! Cuatro ensayos de Historia Nacional Mapuche y un epílogo sobre el futuro (pp. 53-127). Santiago: Lom Editorial.

Martí i Puig, S. M. (2008). "Las razones de presencia y éxito de los partidos étnicos en América Latina. Los casos de Bolivia, Ecuador, Guatemala, México, Nicaragua y Perú (1990-2005)" Revista Mexicana de Sociología, 70(4), 675-724.

Martínez, Christian (2009) "Transición a la democracia, militancia y proyecto étnico. La fundación de la organización mapuche Consejo de Todas las Tierras (1978-1990)", Estudios Sociológicos XXVII: 80.

Martínez, Christian, y Patricia Rodríguez. (2015). "Partisan Participation and Ethnic Autonomy: The Case of the Mapuche Organisation Admapu, in Chile". Journal of Latin American Studies FirstView (octubre).

Mignolo, Walter. (2008), "La opción de-colonial: desprendimiento y apertura. Un manifiesto y un caso", Tabula Rasa n.8 Bogotá ene. /jun.

...........(2007) La idea de América Latina. La herida colonial y la opción decolonial. Gedisa editorial, España.

Naguil, Víctor, 2016. "De la Raza a la Nación, de la Tierra al País. Comunitarismo y Nacionalismo en el movimiento mapuche, 1910-2010", Tesis doctoral en Ciencia política, políticas públicas y relaciones internacionales, Universidad de Barcelona.

Olivares, Alejandro et al (2015) "Los gabinetes ministeriales en la democracia chilena pos 1990: un caso de estabilidad, continuidad histórica y negociación inter-partidaria Cambios de gabinete y supervivencia de los ministros en Chile durante los gobiernos de la Concertación (1990-2010)", DAAPGE año $15, \mathrm{~N}^{\circ} 24$.

Quijano, Anibal. (2011) "Bien Vivir": Entre el "desarrollo" y la des/colonialidad del poder", Ecuador Debate. N॰84 / 77-88.

(2006) "El Movimiento indígena y las cuestiones pendientes en América Latina", Argumentos UAM-X, México.

Pairicán Padilla, Fernando. (2014). Malón: la rebelión del movimiento mapuche 1990-2013, pehuén, Santiago, Chile.

Pereyra, Carlos (1980). “Historias ¿para qué?”, México, Siglo XXI Editores.

Pineda, Cesar (2014) "Mapuche resistiendo al capital y al estado. El caso de la Coordinadora Arauco Malleco en Chile", Latinoamérica. Revista de Estudios Latinoamericanos, Volumen 59.

Pinto, Jorge (2011) "El conflicto Estado-Pueblo Mapuche 1900-1960”, UNIVERSUM, N²7, Vol. 1.

Pinto, Jorge (2016) "Pueblo mapuche, 1810-2015. Dos siglos de lucha por justicia, reconocimiento y respeto". Citado en Namuncura, Domingo et al (2016), Nueva constitución y pueblos indígenas, Editorial pehuén, Santiago, Chile.

Restrepo, Eduardo. (2010). Inflexión decolonial: fuentes, conceptos y cuestionamientos. Editorial Universitaria del Cauca, Colombia.

Richards, Patricia. (2014). "Multiculturalismo neoliberal. Nuevas categorías y formas de entender la ciudadanía y el mundo indígena en el Chile contemporáneo". En Aproximaciones a la cuestión mapuche. Una mirada desde la historia y las ciencias sociales. 
Sousa Santos, Boaventura. (2011) "Epistemologías del sur", Revista Internacional de Filosofía Iberoamericana y Teoría Social, Zulia.

(2013) Descolonizar el saber, reinventar el poder. LOM Ediciones, Chile.

Toledo Llancaqueo, Victor. (2006). Pueblo mapuche: derechos colectivos y territorio: desafios para la sustentabilidad democrática. Santiago de Chile: Programa Chile Sustentable.

Tricot, Tito (2015) "La teluridad del movimiento mapuche autonomista: de la tierra al territorio", pp. 303-327. En Francisco Báez, Leonardo Cancino y Juan Pablo Paredes (Eds.) Acción colectiva y movimientos sociales: disputas conceptuales y casos de estudio recientes. Valparaíso: Editorial Punta Ángeles

Tricot, Tito. (2013). Autonomía, el movimiento mapuche de resistencia, Ceibo, Santiago, Chile.

Tricot, Tito. (2006) La lucha del Pueblo Mapuche, Ilwen Ediciones, Valparaíso

Tricot, Victor. (2013). "Chile: Pasando de la Galería a la Cancha. Partido Político Mapuche Wallmapuwen: Un Instrumento Descolonizador Hacia la Autodeterminación”. En J. Aylwin, S. Martí i Puig, C. Wright, \& N. Yáñez (Eds.), Entre el desarrollo y el buen vivir. Recursos naturales y conflictos en los territorios indígenas. (pp. 293-322). España: Los Libros de la Catarata.

Van Cott, Donna. (2005) From movement to parties. The evolution of ethnic parties, Cambridge University Press.

Verge, Tania. (2014) "Comportamiento político" en LOIS, M. y ALONSO, A. Ciencia política con perspectiva de género, Ediciones akal, España.

Zúñiga, Gerardo (1998) "Los procesos de constitución de Territorios Indígenas en América Latina”, Nueva Sociedad Nro. 153 enero-febrero 